\title{
Struggling International Students in the US: Do University Faculty Know How to Help?
}

\author{
By Susan Unruh*
}

This study explores university faculty members' perspectives on the strengths and challenges of international students in the United States, as well as their own challenges in teaching international students. It also investigates faculty member's practices in making instructional and other accommodations for international students, and probes their knowledge of resources that might be helpful to international students who struggle academically. The study reveals that faculty members typically do not have different methods of working with international students than with domestic students and have limited awareness of resources on campus that might be helpful to international students.

Key words: international students, faculty members' perspectives, campus

\section{Introduction}

International students are a rapidly growing segment of the higher education population in the United States. A report issued by the Institute of International Education (2013) claims that there were 819,644 international students enrolled in US higher education in 2013, a $40 \%$ increase within a decade. The same report says that these students contribute significantly -more than $\$ 24$ billion- to the US economy, with about $72 \%$ receiving most of their funds from sources outside the US. These students mean increased revenues for American institutions of higher education (Bauer \& Picciotto, 2013) and the US economy in general. They also help broaden American students' cultural sensitivities, their international understanding, and their skills in working with diverse populations in an increasingly global society (Lord, 2013; Mamiseishvili, 2012).

While international students stand to benefit from an educational experience in the US, they make considerable sacrifices in leaving homes, families, and sources of social and financial support in their home countries. In addition to language and cultural adjustments, these students deal with visa concerns; they often must struggle to supplement their income while in the US; and they must work to integrate with their American counterparts socially and academically (Bowman, 2012; Lord, 2013). They may well have grown up with different learning and study patterns formed by cultures different than the culture of learning that they encounter in a foreign country (Marambe, Vermunt, \& Boshuizen, 2012). Considering these sacrifices and the benefits gained from hosting international students, it is in the interest of US institutions of higher education to do everything possible to retain them and to help them

*Assistant Professor, Wichita State University, USA. 
persist to the point of degree completion (Mamieseishvili, 2012).

\section{Review of the Literature}

A wide variety of challenges face international students who come to the US for their post-secondary education-challenges of acculturation, low English language competency, difficulties with social and academic integration, even problems with discrimination (McClure, 2007; Msengi, 2003; Wadsworth, Hecht, \& Jung, 2008). There are multiple features of students, cultures, host countries, and schools that have an impact on international students' experiences in adapting to an institution of higher education in the US. For example, Tomich, McWhirter and Darcy (2003) listed 11 factors which seem to influence a person's adaptation to a new culture: "language, cultural similarity/distance, reason/motivation for transition, attachment to home culture, duration of stay, preparation, interaction with host country members, host environment receptivity, gender, and age" (p. 23). Various studies have explored engagement and social interactions of international students in the US (Lee, 2010; Trice, 2004; Zhao, Kuh, \& Carini, 2005). Typically research in this area has focused on gaining the students' perspectives through interviews and surveys. Fewer studies have been done from the perspective of faculty.

In the 1980s, two national surveys of engineering faculty were conducted by Barber and Morgan $(1984 ; 1988)$. The first study attempted to determine whether faculty members believed they had to lower standards for international students in the classroom. Of those surveyed, $87 \%$ reported having the same academic expectations for international and domestic students and $97 \%$ used the same grading standards for both. The second study revealed that engineering faculty believed that American students were better at designing equipment, running experiments, and writing; international students were considered better at conducting theoretically sophisticated research.

In the 1990s, Fallon and Brown (1999) surveyed 46 business faculty from four institutions in the United Kingdom where large numbers of international students were enrolled. They found almost universal agreement among respondents that they valued the opportunity afforded them and their students to learn about other cultures and countries. The majority of respondents agreed that international students helped create a fresh view of the respondent's own subject and broadened the base of class discussions. Eighty-nine percent enjoyed working with international students but $87 \%$ reported language capabilities of non-English speakers to be a problem; $56 \%$ found cultural differences problematic.

In a qualitative study, Trice (2003) interviewed four university faculty members, asking whether they perceived significant differences between international and domestic students in terms of their academic preparation, goals, or performance. The study also probed whether international students "represent unique benefits or challenges for their departments" (p. 380). Challenges for faculty included evaluating and addressing English language 
problems, helping students acquire adequate funding and prestigious US positions, meeting their unique academic needs, integrating them with domestic students, managing domestic students' hesitancy to enroll in classes taught by international students, and managing some faculty members' preference for domestic students. The benefits and contributions of international students were that they provided an international perspective, brought work experiences, helped faculty establish international connections and enhanced the department's international reputation, filled research assistant vacancies, represented some of the highest quality students, and brought domestic students a more accurate perspective of their life circumstances.

The present study updates the previous research on faculty members' perspectives on the strengths and challenges of international students in the US. It investigates the challenges faced by faculty in teaching international students. It also explores faculty's practices in making instructional and other accommodations for international students, and probes faculty's knowledge of resources that would be helpful to international students who are struggling academically.

\section{Method}

\section{Context}

The study took place at a midsize public university located in the Midwest of the United States. The university enrolls approximately 15,000 students; international students make up about $12 \%$ of the entire student population. Most of these international students are undergraduates $(65 \%)$ rather than graduate students $(35 \%)$. The largest numbers of students come from India, followed by Saudi Arabia, China, and Vietnam. An Intensive English Language Center is available for students who need to improve their English proficiency before matriculating to the university. They may take as little as eight weeks to more than a year to complete the program.

\section{The Qualitative Interview}

A qualitative approach was taken in this study in order to allow a more open-ended exploration of the phenomenon of interest, that is, faculty members' perspectives on working with international students in the second decade of the $21^{\text {st }}$ century. Qualitative research encourages the subjects of the study to relate their opinions and thoughts in a rich, deep, and genuine way that is not possible in the typical impersonal survey or questionnaire (Patton, 2002).

A standardized open-ended interview was developed to solicit the interviewees' perspectives on international students. Interviews were conducted by the author and another faculty member in the university's School Psychology program. The standardized open-ended interview format was used 
in order to maximize the use of the interviewees' time, minimize variation between interviewers, and facilitate analyses by making responses relatively easy to compare (Patton, 2002). At the same time, it was important to make the interviews as much like "conversations" as possible, to allow the interviewees' perspectives to comfortably and naturally unfold, and to allow for digressions along the way (Marshall \& Rossman, 2006).

\section{Participants}

Fifteen university professors participated as interviewees in this study. They were recruited using the heterogeneity sampling method, in an effort to learn the themes that cut across a variety of the university's faculty (Patton, 2002). Faculty members known by the investigators were approached for interviews, as well as others who were recommended by interviewees. The distribution throughout the university's colleges and departments is displayed in Table 1.

Table 1. University Faculty Interviewees

\begin{tabular}{|l|c|c|}
\hline College & Department & Number \\
\hline \multirow{4}{*}{ College of Liberal Arts \& Sciences } & Biological Sciences & 4 \\
\cline { 2 - 3 } & Chemistry & 1 \\
\cline { 2 - 3 } & School of Social Work & 1 \\
\cline { 2 - 3 } & Pathematics, Physics and Statistics & 1 \\
\cline { 2 - 3 } College of Education & Counseling & 1 \\
\hline \multirow{3}{*}{ College of Engineering } & Curriculum and Instruction & 1 \\
\cline { 2 - 3 } & Educational Leadership & 1 \\
\hline College of Health Professions & Aerospace Engineering & 2 \\
\cline { 2 - 3 } & Electrical Engineering and & 1 \\
\hline
\end{tabular}

The interviewees had been teaching at the university level for a variety of years: the newest faculty member was in his first semester; four others had been teaching for five or fewer years; two from six to 10 years; three from 11 to 15 years, one from 16 to 20 years; three from 21 to 25 years; and two faculty members had been teaching for 35 years. About half of the interviewees ( 8 of $15)$ were born in the US. The other seven came from four Asian countries.

Some interviewees taught just a handful of international students in a typical semester and some taught a large number. Nine faculty members taught five or fewer international students per semester, two taught between 10 and 20 , two taught between 30 and 40, and two taught 50 or more per semester. Five said that they taught only graduate students, four taught only undergraduates, and six taught both graduates and undergraduates.

Interviewees were asked about how many home countries were represented among their international students. Eight interviewees said that their students came from over five home countries, four had students coming 
from three to five home countries, and three had students coming from one or two home countries. Of the countries mentioned, Asian countries predominated, followed by countries in the Middle East.

\section{Data Analysis}

\section{Strengths of International Students}

After eliciting demographic information about the interviewees, the study began by asking them about the strengths of international students. There was wide agreement that they tend to be motivated, committed, focused, goaloriented, and determined to succeed. These qualities were mentioned as strengths by a majority of the interviewees. One professor said: "They are committed and determined. It takes so much effort for them to come here, to get accepted and then to move here. They are hard workers and very goal oriented. You don't always find that in US students, even at the graduate level."

Following commitment and determination, the next most agreed-upon strengths were that international students are smart (e.g., they have superior powers of analysis, they want to understand things better, and their scholarship is strong) and that they tend to have stronger science and math skills than domestic students; students from India and China are especially strong in these areas. After that, the most frequently mentioned strengths were in the areas of work ethic, conscientiousness, and in their perspectives on cultural competency and diversity. One professor mentioned their "broad outlook of the world; they seem to be more experienced than other students in terms of being welltraveled... and they often speak several languages." Finally, a couple of instructors valued their flexibility, adaptability, and respectfulness.

\section{Challenges and Struggles of International Students}

Data regarding the struggles and challenges for international students were solicited in two ways. First, interviewees were asked: "What do you see as the biggest challenges facing international students?" Later in the interview, they were asked: "On a scale of 1 to 5, with 1 being "very little" and 5 being "a large extent", when international students struggle in your classes, to what extent do you believe that their difficulties are due to one of the following?" Each faculty member was asked about the following:

- english language proficiency;

- learning and study strategies;

- cultural differences;

- lack of familiarity with the campus and available resources;

- insufficient prerequisite skills for your class; 
- differences in teaching methods or instructional practices.

For the purposes of this study, ratings of 3 or greater were considered indications of problems.

English language fluency. One of the biggest challenges for international students is that of fluency with the English language; two/thirds of the respondents listed it as a challenge. Several difficulties related to language fluency were noted.

- Some academic tasks just take longer to complete for international students, such as reading assignments and taking tests. It can be cumbersome for the students when "they have to go back and forth" when translating material.

- Related to the language issue, professors struggle with whether or not to let students use electronic translators during tests. One professor noted that he does not not want language to be a barrier on tests; however, it is difficult to know how much information students are getting when they use a translator. He allows the use of translators during tests but fears that international students may be accessing some of the information needed to answer the test questions, rather than just getting material translated. $\mathrm{He}$ said he did not like it when a student was presumably looking up the meaning of a word during a test and "I don't see a couple of words, I see a whole paragraph" on the translator.

- One instructor noted that the amount of time international students have to study the English language may not be long enough prior to starting university classes, even though test scores may show that they have sufficient fluency. Another remarked that the accents of international students are sometimes difficult to understand.

- It may be hard to place students in courses at the correct level and to determine what students have in terms of prerequisites due to language issues, according to some of the interviewees. One professor told of a young Japanese student with barely any English who was placed in an algebra class. The professor said: "When there was no talking and it was just the math, he was doing really well and this was the first day. So I started writing harder and harder questions and then I started putting down trig(onometry) questions and then transferred him to Calculus 1. Because he didn't need algebra and trig; he just didn't know how to say it. $\mathrm{He}$ didn't know how to tell anyone in the Math Department that he already understood."

- A professor said that it can be difficult for international students to benefit from professional counseling if they need help with personal problems. $\mathrm{He}$ said: "You can send them to the student counseling center but perhaps, after one or two sessions, you find that it's difficult to continue because (they are dealing with) "in-depth" feelings that are not easy to express in fluent English situations." 
Cultural differences. The challenges of cultural differences were rated as a source of struggle for their international students by several of the interviewees. Two-thirds rated cultural differences as a source of problems when international students struggle. Different problematic aspects of adapting to the culture were mentioned by several faculty members.

- When international students struggle, $40 \%$ of faculty respondents rated "Differences in teaching methods or instructional practices" as being a source of the problem. International students may not be accustomed to the American student's typical relationship with his or her teachers. A professor originally from Taiwan explained: "Their perception of a teacher is very different than the American student perception of a teacher. They hold a teacher in high regard. We have a saying: "One day a teacher is a teacher for life." So that personal touch is very important. It is the encouragement that makes them continue through the process."

- There can be misunderstandings about class procedures and "the politics of education in the US." A professor remarked that it can be a problem "just understanding the way things work, such as etiquette. Sometimes international students will just walk into my office without knocking or setting up an appointment. But when they make an appointment, they usually arrive on time."

- One professor mentioned the possible variations in the definitions of plagiarism in different cultures or countries. He commented: "There are certain broad geographical areas at which it appears to be absolutely okay to plagiarize or cheat, using whatever information is available." Indeed, research on academic integrity confirms that there are differing outlooks across cultures. In an article entitled: "Guide to Advising International Students about Academic Integrity," Gillespie (2012) says that "plagiarism is a Western ideal" that stems from ideas about freedom of speech and individual property (copyright). She provides evidence that in certain cultures it is considered a form of respect to use an author's own words and that attribution is not expected, making it difficult for these students to understand a Western definition of plagiarism.

- Another professor mentioned that students trained outside of a Western culture may not have a good understanding of the "research culture or how to be scientists." She said that students "need to establish their own research agenda. When they're working on a research project, they should know more than I do about it."

Prerequisite skills. A professor in a medical field shared her concern about the reactions of some patients to international students: "Sometimes a patient makes a judgment about the student and doesn't want them to care for them, which is devastating for the student. The patient may make racial comments or ask inappropriate questions." 
Modifying instruction. Interviewees were asked if they ever modified instruction for international students. The majority (11) said that they did not. One professor said that when she began teaching she had a class that was composed of about $70 \%$ international students. Her department chair suggested that she put all of her announcements on the board for the students who might not completely understand what she was saying. She began doing that and found that it was helpful to all students. Two professors said that they give them extra time to complete a paper or a test. Another professor said that he tries to limit his use of American slang.

Modifying assignments and tests. Only two of the interviewees said they modify assignments or tests for international students. One faculty member said he gives extra time on tests and the other said he has modified test and assignment dates because of international traveling schedules. For one student who was quarantined because of tuberculosis, he recorded his lectures and modified his assignment due dates so the student could keep up.

How faculty respond when international students struggle. Interviewees were asked: "How do you handle it if you see an international student struggling in your classes?" About a third of the interviewees said that they would have a one-on-one conference with the student. In the conference, they might ask the student whether he or she understood the lectures.

The next most likely response, though, was to take the attitude that these students are adults; it is up to them to take the initiative on such problems, and it would be handled the same for both international and domestic students. One interviewee said: "I handle it no different than I would a domestic student. Typically, I don't intervene in any way unless they seek me out. So if they come to my office and ask me what they might do to improve their performance in my class - whether they be domestic or international-I have a long conversation with them. Try to find out what they are currently doing, how much time and energy they are currently putting into their class work. And then try to help them decide what it is that they can do to change. It's nothing I can do, so it has to be some change that they make in their approach to the course." One professor took a radically different approach than this, however, and started up a support group for international students.

Some faculty said it is necessary to spend more time with international students, especially when written papers are required for the course. One professor indicated that he enlists the aid of the Office of International Education. A couple expressed the need for faculty to know more about what kinds of resources are available for struggling international students. When asked to what extent lack of familiarity with the campus and available resources was a problem for struggling students, over half of the faculty interviewed rated it as a source of difficulty for their struggling international students. 


\section{Discussion}

The focus of this study was to explore the academic challenges faced by international students and to learn more about faculty's approaches regarding how to help them succeed. An individual's strengths can often be used to help meet challenges that are encountered. The strengths of international students mentioned by faculty give clues as to how these students are able to persist in earning university degrees in a foreign country speaking a second language. Faculty see these students as motivated, committed, focused, goal-oriented, and determined to succeed. They are smart and tend to have stronger science and math skills than domestic students. They have a strong work ethic and are conscientious and respectful. They are culturally competent, flexible, and adaptable. These are all highly-prized attributes-not only of students but also of employees.

Stacked against these strengths are some daunting challenges. As found in previous studies, competency in oral and written English continues to be the central challenge for international students. Faculty members struggle with how to accommodate for lack of English proficiency. Some recognize that it demands that they devote more time to these students. Faculty may lose a sense of control during exams when they allow students to use electronic translators. However, none of the interviewees indicated that they had different standards for international students or that they graded them differently.

Raising the bar on English proficiency skills for admittance to a university is always an option mentioned when international students struggle with reading, writing, speaking, and listening skills. In this university, most students spend about a year in intensive English language study before being able to pass a test at the level sufficient to gain them admittance. The case can also be made for providing additional services for students to help them with oral and written English language skills after they have matriculated. Some students are more comfortable and more proficient with oral English (speaking and listening), others with written English (reading and writing).

The issue is complex, according to Bauer and Picciotto (2013), who say: $(F)$ or international students there are often specific gaps in information or vocabulary resulting from a lack of experience with American education: simply not knowing what the conventions and expectations of American university discourse might be, or what the particular terms that are often central to American writing assignments might mean (p. 79).

There are cultural adjustment challenges that continue to plague international students, such as different relationship patterns and etiquette between the US culture and other cultures. Also of concern are cultural differences in the definitions of academic integrity, specifically plagiarism. Although some instances of plagiarism among international and domestic students are certainly deliberate acts of dishonesty, there are also instances of 
"inadvertent" plagiarism (Duff, Rogers, \& Harris, 2006), in which international students from non-Western cultures fail to cite sources because of ignorance of the cultural expectations or lack of skill in citing references. A study at the University of South Australia (Duff, Rogers, \& Harris, 2006) significantly reduced the instances of deliberate or inadvertent plagiarism through "carefully planned teaching methodologies aimed at making Western requirements explicit" (p. 680). The university in the present study provides a training module on its website regarding plagiarism, which explicitly teaches how to cite sources in written papers. It would be helpful for this training to be provided in the students' home languages and, perhaps, to require documentation that the students had completed the training prior to beginning classes. It can be very award for faculty to confront students about plagiarism, not to mention the possible feelings of shame engendered in the students during such a confrontation.

Very few of the faculty members reported modifying instruction, assignments, or tests for their international students, although there was some recognition that international students require extra time because they are operating in a non-native language. The need to modify instruction, assignments, and tests for English language learners at the elementary and secondary levels is relatively well-established in the US (Abedi, 2004; Coleman, 2012; or the website Colorín Colorado, 2014). It is not known whether university faculty members do not make such accommodations because they do not believe it should be necessary or because they are not aware of what kinds of accommodations might be helpful to the students.

At this university, there are several resources that can be of service to students who are struggling academically. Most faculty members are aware of the services of the Counseling and Testing Center; interviewees spoke about referring students there for mental health issues. Another well-known service is provided by the Writing Center. The university's Office of International Education is a strong advocate for international students but it was only mentioned as a resource by three of the interviewees. There is also a Student Support Services office which provides free tutoring services for any course at the undergraduate level; this was not mentioned by any of the interviewees.

\section{Limitations}

This study shares limitations that are inherent in any qualitative research. Interviewees consisted of a sample of convenience; it is not known to what extent they are representative of university faculty as a whole. 


\section{Directions for Further Research}

An exploratory qualitative research design can be extremely fruitful in suggesting further topics of study. A future study regarding the acceptability among faculty of possible accommodations for academically struggling international students would be informative. One topic evoked by the present study is that of surveying international students regarding their needs for academic supports that are not currently in place but that might be very useful in helping them accomplish their academic goals. Based on faculty responses in this study, there appears to be a need for continuing intensive support in English language skills after admission to a university, especially in writing. The provision of such a service and its impact could be an area of fruitful research.

\section{Acknowledgments}

Thanks to Nancy A. McKellar, Ph.D. for her invaluable help in conducting the research and reading the manuscript.

\section{References}

Abedi, J. (2004). Will you explain the question? Principal Leadership: High School Edition, 4(7), 27-31.

Barber, E. G., \& Morgan, R. P. (1984). Engineering education and the international student: Policy issues. Engineering Education, 74, 655-659.

Barber, E. G., \& Morgan, R. P. (1988). Boon or Bane: Foreign Graduate Students in US Engineering Programs. (IIE Research Report Series No. 15). New York: Institute of International Education.

Bauer, H., \& Picciotto, M. (2013). Writing in America: International students and first-year composition. Writing on the Edge, 23(2), 75-86.

Bowman, K. D. (2012). Beyond the comfort zone. International Educator, (Spring, 1993), 56-59.

Coleman, R. (2012). The common core challenge for ELLs. Principal Leadership, 12(6), 46-51.

Colorín Colorado (2014). Retrieved from http://www.colorincolorado.org/

Duff, A. H., Rogers, D. P., \& Harris, M. B. (2006). International engineering studentsavoiding plagiarism through understanding the Western academic context of scholarship. European Journal of Engineering Education, 31(6), 673-681.

Fallon, G., \& Brown, R. B. (1999). What about the workers? Academic staff opinion about working with non-UK postgraduate students in higher education. Journal of Further and Higher Education, 23, 41-52.

Gillespie, G. M. (2012). Guide to advising international students about academic integrity. The Mentor: An Academic Advising Journal, (March 2, 2012). Retrieved from: http://bit.ly/1ySihUw

Institute of International Education. (2013). Open doors 2013: Data highlights. Retrieved from: http://bit.ly/1DDxapr 
Lee, J. J. (2010). International students' experiences and attitudes at a US host institution: Self-reports and future recommendations. Journal of Research in International Education, 9(1), 66-84.

Lord, M. (2013). Delivering diversity. American Society for Engineering Education (ASEE) Prism, 23(1), 26-31.

Mamiseishvili, K. (2012). International student persistence in US postsecondary institutions. Higher Education, 64, 1-17.

Marambe, K. N., Vermunt, J. D., \& Boshuizen, H. P. A. (2012). A cross-cultural comparison of student learning patterns in higher education. Higher Education, 64, 299-316.

Marshall, C., \& Rossman, G. B. (2006). Designing qualitative research, fourth edition. Thousand Oaks, CA: Sage.

McClure, J. W. (2007). International graduates' cross-cultural adjustment: Experiences, coping strategies, and suggested programmatic responses. Teaching in Higher Education, 12(2), 199-217.

Msengi, I. G. (2003). Sources of stress and its impact on health behaviors and academic performance of intemational students at a comprehensive Midwestern University. International Journal of Global Health and Health Disparities, 5(1), 55-69.

Patton, M. Q. (2002). Qualitative research and evaluation methods (3rd ed.). Thousand Oaks, CA: Sage.

Tomich, P. C., McWhirter, J. J., \& Darcy, M. U. A. (2003). Personality and international students' adaptation experience. International Education, 33(1), 2239.

Trice, A. G. (2003). Faculty perceptions of graduate international students: The benefits and challenges. Journal of Studies in International Education, 7(4), 379403.

Trice, A. G. (2004). Mixing it up: International graduate students' social interactions with American students. Journal of College Student Development, 45(6), 671687.

Wadsworth, B. C, Hecht, L. M., \& Jung, E. (2008). The role of identity' gaps, discrimination, and acculturation in international students' educational satisfaction in American classrooms. Communication Education, 57(1), 64-87.

Zhao, C., Kuh, G. D., \& Carini, R. M. (2005). A comparison of international student and American student engagement in effective educational practices. The Journal of Higher Education, 76(2), 209-231. 